\title{
Impact of immediate initiation of antiretroviral therapy among men who have sex with men infected with HIV in Chengdu, southwest China: trends analysis, 2008-2018
}

Chenyao Wu', Baiyang Zhang ${ }^{1}$, Zhen Dai ${ }^{2}$, Qianwen Zheng ${ }^{1}$, Zhenhua Duan², Qinying He ${ }^{2^{*}}$ and Cairong Zhu ${ }^{{ }^{*}}$

\begin{abstract}
Background: Given the rampant HIV epidemic among men who have sex with men (MSM) in Chengdu, southwest China, Treat All policy, defined as immediate antiretroviral therapy (ART) initiation after HIV diagnosis, was implemented since 2014. Real-world research evaluating impacts of immediate ART on HIV epidemics is needed to optimize policy-making as national and international guidelines have been lowering ART eligibility threshold. The purpose of this study is to: assess temporal trends of the HIV epidemic and impacts of Treat All policy among MSM; and lay foundation for HIV-related policy evaluation using longitudinal routine data from health information systems.

Methods: Data used in this study were HIV sentinel seroprevalence, annual reported HIV cases and ART coverage rate among MSM in Chengdu from 2008 to 2018, derived from national HIV/AIDS information system. Temporal trends of the HIV epidemic were described using Joinpoint Regression Program. Interrupted time-series method was deployed to evaluate Treat All policy.
\end{abstract}

\footnotetext{
* Correspondence: cairong.zhu@hotmail.com; 78004693@qq.com

${ }^{2}$ Department of AIDS\&STD Control and Prevention, Chengdu Center for

Disease Control and Prevention, 610041 No. 4 Longxiang Road, Sichuan, Chengdu, China

'Department of Epidemiology and Health Statistics, West China School of Public Health and West China Fourth Hospital, Sichuan University, 610041

No. 17 Section 3, Renmin South Road, Chengdu, Sichuan, China
}

C C The Author(s). 2021 Open Access This article is licensed under a Creative Commons Attribution 4.0 International License, which permits use, sharing, adaptation, distribution and reproduction in any medium or format, as long as you give appropriate credit to the original author(s) and the source, provide a link to the Creative Commons licence, and indicate if changes were made. The images or other third party material in this article are included in the article's Creative Commons licence, unless indicated otherwise in a credit line to the material. If material is not included in the article's Creative Commons licence and your intended use is not permitted by statutory regulation or exceeds the permitted use, you will need to obtain permission directly from the copyright holder. To view a copy of this licence, visit http://creativecommons.org/licenses/by/4.0/. The Creative Commons Public Domain Dedication waiver (http://creativecommons.org/publicdomain/zero/1.0/) applies to the data made available in this article, unless otherwise stated in a credit line to the data. 
(Continued from previous page)

Results: HIV sentinel seroprevalence rose from 11.20\% in 2008 to 17.67\% in 2013 and Annual Percent Change (APC) was $8.25 \%(95 \% \mathrm{Cl}-2.40 \%, 20.07 \%)$, then decreased to $5.17 \%$ in 2018 (APC $=-19.63 \%, 95 \% \mathrm{Cl}-27.54 \%$, 10.86\%). Newly reported HIV cases increased from 168 cases in 2008 to 1232 cases in 2015 (APC = 26.99\%, 95\% Cl $21.32 \%, 32.93 \%)$, and reduced to 1014 cases in 2018 (APC $=-8.80 \%, 95 \% \mathrm{Cl}-18.45 \%, 2.01 \%)$. ART coverage rate has been climbing from 11.11\% in 2008 to 92.29\% in 2018 and Average Annual Percent Change was 16.09\% (95\% $\mathrm{Cl} 11.76 \%, 20.59 \%)$. Results of interrupted time-series models showed that compared to an annual increase of $0.87 \%$ during pre-policy period, there was a decline of 3.08\% (95\% Cl $-0.0366 \%,-0.0250 \%)$ per year of HIV sentinel seroprevalence since 2014; and compared to an annual increase of 116 cases before 2014, there was an annual drop of 158 newly reported HIV cases (95\% Cl - 194.87\%, - 121.69\%) during the post-policy period.

Conclusions: Immediate ART after HIV diagnosis could potentially curb HIV transmission at population level among MSM, along with other strategies. Future assessment of HIV prevention and control policy can be carried out using routinely collected longitudinal data from health information systems.

Keywords: HIV infections, Homosexuality, male, Antiretroviral therapy, highly active, HIV seroprevalence, Health policy, Interrupted time series analysis

\section{Background}

The HIV pandemic continues to be a major global public health issue. World Health Organization (WHO) estimated there were approximately 37.9 million people living with HIV (PLHIV) by the end of 2018 [1]. The distribution of China's HIV epidemics is unbalanced by geographic region and subpopulation group. Both prevalence and incidence of HIV are especially high in southwest China, and men who have sex with men (MSM) bear a disproportionate burden of HIV [2], accounting for $25.5 \%$ of national new HIV infections in 2018, rising from $2.5 \%$ in 2006 [3, 4].

MSM, whose risk of acquiring HIV is 22 times higher than the general population, are listed as key population in the HIV pandemic by the Joint United Nations Program on HIV and AIDS (UNAIDS) [5]. Preventive measures such as condom use help contain HIV infection [6], but they don't reduce infectiousness (defined by plasm viral load) or HIV-related morbidity for PLHIV. Whilst antiretroviral therapy (ART) can optimize health outcomes for PLHIV and reduce onward HIV transmission by lowering plasm viral loads [7-9]. Specially, starting ART at early stages of infection, compared with a deferred initiation, has been proved to have individuallevel benefits, including less morbidity and mortality and reduced rate of linked partner transmissions [10-17]. Based on clinical significance of immediate ART after HIV diagnosis and development of new antiretroviral drugs with fewer treatment-related toxic effects [10, 12, 17-22], CD4+ cell threshold eligible for ART in both national and international guidelines for HIV treatment has been relaxed to shorten time from diagnosis to ART in recent years [23, 24]. Nevertheless, several randomized controlled trials found that HIV incidence in the study population wasn't substantially reduced in the context of immediate ART for all PLHIV [25-27].
Despite the individual-level benefits, impacts of immediate ART on HIV infection at population level is unknown. Mathematic models predicted that, among MSM, early ART might reduce HIV incidence and prevalence [28, 29], pending further empiric evidence (we used early ART, immediate ART and Treat All interchangeably). Real-world research has been listed as high priority area in MSM HIV prevention and control [30], whereas there are limited researches evaluating the effects of HIV policies targeted at MSM in a real-world setting. Real-world policy evaluation is necessary to provide empiric evidence for policy makers and health care workers. Hence real-world researches in MSM HIV epidemics are urgently needed, given the especially high HIV incidence among MSM, to mitigate the knowledge gap and facilitate policy making in MSM HIV prevention and control [30].

Sichuan province, the most populous and developed region in southwest China, has ranked first nationally with annual reported HIV cases for years [31]. The provincial capital of Sichuan province, Chengdu, is one of the five urban regions in China where HIV is spreading at an alarming rate with substantial increases in MSM population [2]. Given the raging HIV epidemic among MSM in Chengdu [2], the local Center for Disease Control and Prevention (CDC) determined that Treat All policy be implemented among MSM since 2014; under this policy, MSM can receive free ART immediately after HIV diagnosis regardless of CD4+ cell count. Treat All policy began two years earlier prior to the 2016 national and WHO guidelines recommending ART be offered to all HIV-positive adults and adolescents, irrespective of CD4+ cell count. With national and international guidelines lowering ART threshold, assessment of Treat All policy should be performed since its implementation, to shed a light on whether "treat all" helps to contain the 
HIV epidemic and set an example for studies of this kind.

The purpose of this study, therefore, is to assess temporal trends of the HIV epidemic and ART coverage among MSM in Chengdu before and after Treat All policy; to evaluate impacts of Treat All policy on MSM HIV infection at population level; and to lay foundation for HIV policy evaluation using longitudinal administrative data, as well as provide evidence for policy makers to further improve early HIV treatment outcomes.

\section{Methods}

\section{Study design}

This is a retrospective study using longitudinal and routinely collected data from national health information system between 2008 and 2018 .

\section{Data source and indicators}

Indicators analyzed in this study were: HIV sentinel seroprevalence, newly reported HIV cases and ART coverage rate among MSM whose address was Chengdu city. The indicators were aggregated or calculated for each year between 2008 and 2018, using data derived from National HIV/AIDS Comprehensive Response Information Management System (CRIMS). After years' development since 1990's, China's web-based HIV information system was established in 2005 to promote timely reporting and data quality. With improvements and expansion of HIV/AIDS data collection, a multifaceted web-based HIV/AIDS information system called CRIMS was put into operation since 1st January 2008. To ensure data quality and completeness, there are laws regulating data collecting process, staff training, operational manual for CRIMS and quality assessments carried out annually, thereby data from CRIMS can be deemed as reliable for our analyses.

As part of CRIMS, China's HIV surveillance comprises two main databases: (1) routine online HIV case reporting by health care providers at all levels, legally mandated by national regulations; (2) HIV sentinel surveillance annually collecting cross-sectional data including HIV serostatus in sentinel sites across China, to consecutively monitor HIV epidemic situations among key affected populations [32-35]. Chengdu is a southwest sentinel site of National HIV Sentinel Surveillance System, and MSM have been its key monitoring group since 2004. Besides, databases of HIV counseling and testing, ART management and the like are parts of CRIMS as well. More detailed information about data collection, management and quality control can be found in previous study [36].

Data from HIV surveillance (HIV seroprevalence and newly reported HIV cases) reflect trends of the HIV epidemic and have been used in many studies [2, 4, 37, 38], information from the data can be regularly applied by policy makers to optimizing HIV prevention efforts. HIV sentinel surveillance and routine HIV case reporting provide valuable and perhaps the only reliable information about HIV epidemic situations as well as evidence for HIV policy evaluation among MSM [39, 40], under the circumstance that MSM come from a hidden and stigmatized population whose size is hard to estimate [41].

\section{HIV sentinel seroprevalence}

HIV sentinel seroprevalence, defined as the proportion of the sampled MSM who are tested and confirmed as HIV infected in the annual sentinel survey which is conducted at fixed locations and lasts from April to June every year since 2005. It was calculated with number of sampled MSM in the annual sentinel survey conducted in Chengdu as denominator and confirmed HIV cases from those MSM as numerator.

HIV sentinel surveillance is in the charge of local CDCs designated by national health authority and executed in accordance with Operational Manual of The National AIDS Sentinel Surveillance Program. According to the Operational Manual, MSM found to be previously HIV infected should be included, and sample size depends on HIV prevalence (250 if prevalence more than $10 \%, 400$ otherwise for MSM). The MSM population in HIV sentinel surveillance is defined as men who had oral or anal intercourse with other males within the past year. Sampling methods are as below: (1) snowball sampling; (2) recruitment from venues frequented by MSM like gay bars; (3) recruitment via networks. After informed consent is signed, 3 to $5 \mathrm{~mL}$ venous blood is sampled for HIV serological test and HIV serostatus is determined by corresponding technical guidance.

\section{Newly reported HIV cases}

Newly reported HIV cases used in this study were newly confirmed cases registered in CRIMS whose route of HIV infection was male homosexual transmission and address was Chengdu city. Annual reported HIV cases were aggregated from 2008 to 2018.

Given the hidden and stigmatized nature of MSM [39], it's deemed that newly reported HIV cases is a marker for HIV incidence, and trends in new HIV cases have been found to be consistent with trends in estimates of HIV incidence [42-44].

\section{ART coverage rate}

ART coverage rate is defined as the percentage of living HIV-positive MSM registered in CRIMS who have been receiving ART. MSM in the treatment database (after receiving treatment) were linked to their own records in the epidemiology database (after confirmed as HIV 
positive). It was calculated with number of registered alive MSM HIV cases whose address was Chengdu city as denominator and linked cases receiving ART as numerator.

Changes of ART coverage can reflect changes in CD4+ cell count threshold for ART eligibility. Increasing coverage was found to be related to a decreasing threshold [13], thereby ART coverage can be used to directly reflect effects of the treatment eligibility threshold changes.

\section{Statistical methods}

Temporal trends analysis was conducted with Joinpoint Regression Program (Version 4.7.0.0 - February 2019, National Cancer Institute) to depict HIV seroprevalence, newly reported HIV cases and ART coverage among MSM in Chengdu from 2008 to 2018. In this approach, Joinpoint models that best fitted the data were built and corresponding temporal trend curves were drawn, assuming the change in outcome variable is constant over each time partition defined by the transition points (called joinpoints), but varies among different time partitions. Annual Percent Change (APC) and Average Annual Percent Change (AAPC) reflect relative change of outcome variable. APC is an estimated annual percentage change where the outcomes of interest are assumed to change at a constant percentage of that of the previous year. AAPC is a summary measure of the trend to describe the average APCs over a period of multiple years.

Interrupted time-series (ITS) method was applied to evaluate impacts of Treat All policy on HIV transmission at population level among MSM [45]. By using longitudinal and routinely collected data from health systems before and after a policy intervention, ITS analysis can evaluate impacts of health policies on outcome of interest without requiring a control site. This method was based on fitting segmented linear regression model, which divided the time series into pre-policy (including 6 data points from 2008 to 2013) and post-policy (including 5 data points from 2014 to 2018) segments. Analysis was performed using Stata 14.0 (StataCorp. 2014).

The following model was established for ITS analysis [46]:

$y_{t}=\beta_{0}+\beta_{1} *$ time $+\beta_{2} *$ policy $+\beta_{3} *$ postslope $+\varepsilon_{t}$, where $y_{t}$ was the outcome variable at different time points, variable time indicates time points and was coded number 1-11 corresponding to 2008-2018 in year. Variable postslope was coded 0 up to the last point before the policy intervention and coded sequentially from 1 thereafter. $\beta_{0}$ estimates the baseline level of $y_{t}$ at the beginning of the time series. $\beta_{1}$ estimates the structural trend or natural growth rate of $y_{t}$, independently from the policy intervention. $\beta_{2}$ estimates the change in level of $y_{t}$ due to policy intervention (policy $=0$ and policy $=1$ indicate before and after the policy intervention respectively), reflecting immediate impact of the policy. $\beta_{3}$ estimates the change in trend of $y_{t}$ after the policy intervention, reflecting the long-term effect of the policy. $\beta_{2}$ and $\beta_{3}$ represent absolute annual change of outcome variable. $\beta_{2}$ answers whether there's an immediate impact of, while $\beta_{3}$ answers whether there's a long-term or sustained impact of the policy intervention. $\varepsilon_{t}$ is the random error at time points [46].

Our outcomes of interest were HIV sentinel seroprevalence and annual reported HIV cases, a visual examination was used to assess the trend or nonstationary characteristics of the data. Then possible autocorrelation between values at serial time points was assessed using the Durbin-Watson test, where both outcome variables showed autocorrelation. Hence generalized least squares estimator was applied, using PraisWinston method to correct data autocorrelation [47].

The overall significance level was $a=0.05$.

\section{Results}

HIV sentinel seroprevalence and temporal trend

HIV sentinel seroprevalence among MSM in Chengdu showed a rising trend from $11.20 \%$ in 2008 to $17.67 \%$ in 2013, then dropped all the way to $5.17 \%$ in 2018 (Table 1). Annual Percent Change (APC) between 2008 and 2013 was $8.25 \%$ (95\% CI $-2.40 \%, 20.07 \%)$, which wasn't statistically significant, entailing uncertainty about the change direction of the trend before 2014. The significantly negative APC of 2013-2018 (-19.63\%, 95\% CI $-27.54 \%,-10.86 \%)$ reflected a downward trend of HIV seroprevalence after Treat All policy intervention (Fig. 1). Besides, Average Annual Percent Change (AAPC) of 2008-2018 (- 6.72\%, 95\% CI - 12.04\%, - 1.09\%) was significantly below zero, indicating an overall declining trend over the observation period.

\section{Newly reported HIV cases and temporal trend}

Newly reported HIV cases among MSM in Chengdu rapidly increased from 168 cases in 2008 to 1232 cases in 2015 , then decreased to 1014 cases in 2018 , remaining at a relatively high level during post-policy period compared with that in earlier years (Table 1). APC was 26.99\% (95\% CI 21.32\%, 32.93\%) between 2008 and 2015, suggesting a significant upward trend during this period. APC of 2015 to 2018 was $-8.80 \%$ (95\% CI $18.45 \%, 2.01 \%)$, nonsignificant and entailing uncertainty about the change direction of the trend after 2014 (Fig. 2). While AAPC over 2008 to 2018 was 14.99\% (95\% CI 10.79\%, 19.34\%), with an upper 95\% CI limit smaller than the lower 95\% CI limit of the APC of 2008 
Table 1 HIV sentinel seroprevalence, newly reported HIV cases and ART coverage rate among MSM in Chengdu between 2008 and 2018

\begin{tabular}{|c|c|c|c|c|c|c|c|c|c|c|c|}
\hline & 2008 & 2009 & 2010 & 2011 & 2012 & 2013 & 2014 & 2015 & 2016 & 2017 & 2018 \\
\hline HIV sentinel seroprevalence (\%) ${ }^{a}$ & 11.20 & 13.33 & 14.15 & 15.50 & 13.90 & 17.67 & 13.83 & 12.90 & 7.90 & 8.78 & 5.17 \\
\hline Newly reported HIV cases ${ }^{b}$ & 168 & 340 & 367 & 528 & 639 & 824 & 1061 & 1232 & 1124 & 1021 & 1014 \\
\hline ART coverage rate $(\%)^{c}$ & 11.11 & 14.56 & 25.71 & 40.24 & 47.16 & 57.51 & 65.57 & 78.40 & 85.21 & 90.21 & 92.29 \\
\hline
\end{tabular}

${ }^{a}$ calculated with number of sampled MSM in the annual sentinel survey conducted in Chengdu as denominator and confirmed HIV cases from those MSM as numerator

${ }^{b}$ newly confirmed HIV cases in CRIMS whose route of infection was male homosexual transmission and address was Chengdu city

c calculated with number of alive MSM HIV cases registered in CRIMS whose address was Chengdu city as denominator and linked cases receiving ART as numerator

to 2015 , indicating a slower growing rate on average over 2008 to 2018 than that during 2008 to 2015.

\section{ART coverage rate and temporal trend}

ART coverage rate among MSM in Chengdu has been climbing over the span of 2008 to 2018: from $11.11 \%$ in 2008 to $92.29 \%$ in 2018 (Table 1). APC between 2008 and 2015 (21.30\%, 95\% CI 13.45\%, 29.68\%) was higher than that of 2015 to 2018 (APC $=4.79 \%, 95 \%$ CI 2.03\%, 7.62\%), implying ART coverage rate grew quickly prior to 2015 and then slightly increased, gradually stabilizing at a high level ever since Treat All policy was implemented (Fig. 3).

\section{Interrupted time-series analysis}

Table 2 displays the results of segmented linear regression model 1 and 2 built to evaluate the impacts of Treat All policy on HIV sentinel seroprevalence and annual reported HIV cases respectively among MSM in Chengdu.
Results of Model 1(Table 2) demonstrated that no significant change in the level of HIV sentinel seroprevalence was observed immediately after the policy roll-out. The statistically significant natural growth rate showed an absolute year-to-year increase of $0.87 \%$, indicating there would have been an annual rise of $0.87 \%$ on average of HIV sentinel seroprevalence had the treatment policy change not been implemented. The change in trend showed a significant absolute decrease of $3.08 \%$ of HIV sentinel seroprevalence on average each year since the policy implementation. Model 1 predicted that HIV sentinel seroprevalence among MSM in Chengdu would have reached $20.80 \%$ in 2018 without the intervention, while the actual figure was $5.17 \%$ for that year. Therefore, the absolute effect of Treat All policy was a significant drop of $15.63 \%$ in HIV seroprevalence, equating to a relative $75.14 \%$ decrease, four years after the treatment policy intervention.

According to Model 2 (Table 2), annual reported HIV cases had an average increase of about 116 cases per

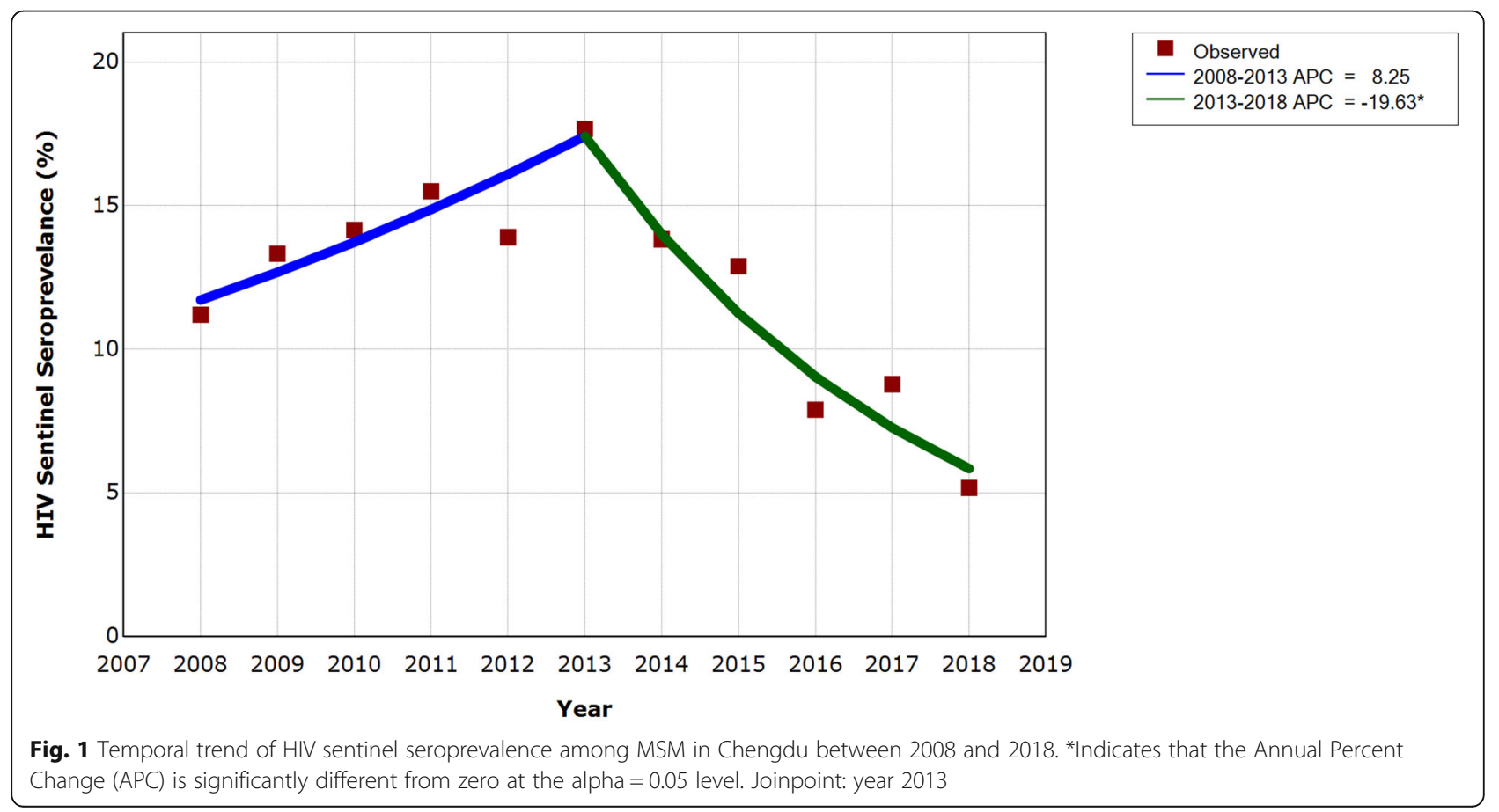




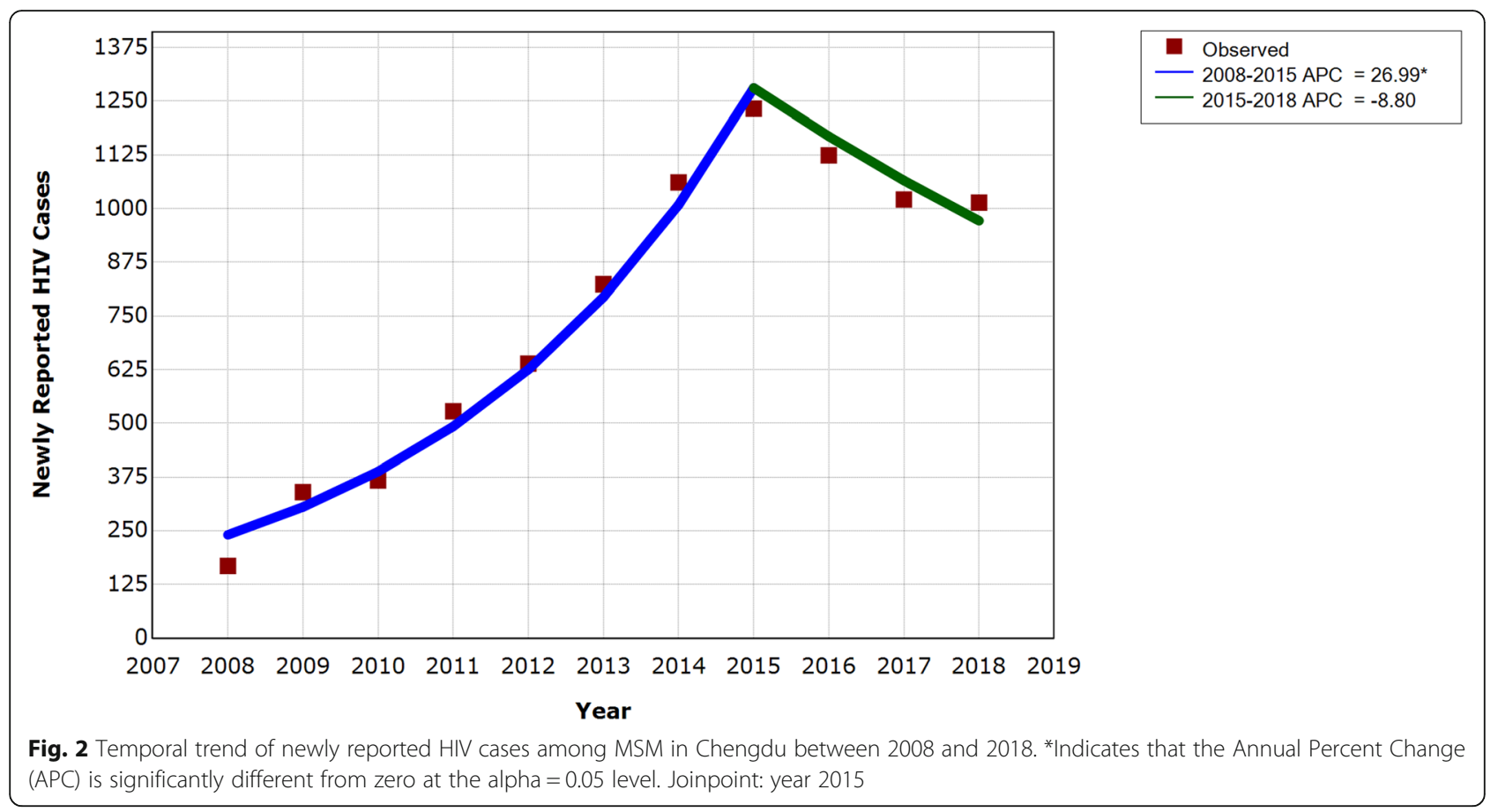

year during the pre-policy period, indicating 116 more cases would have been reported annually than the previous year had the treatment policy intervention not been implemented. A significant increase immediately after the policy implementation was observed, and we found a downward trend where there was a decrease of about 158 cases each year during the post-policy period, indicating on average some 158 fewer HIV cases were reported annually since the policy implementation. Model 2 estimated that annual reported HIV cases among MSM in Chengdu would have been 1344 cases in 2018 without the intervention, while the real number was 1014 cases that year. Therefore, the absolute effect of Treat All policy was a significant reduction by 330

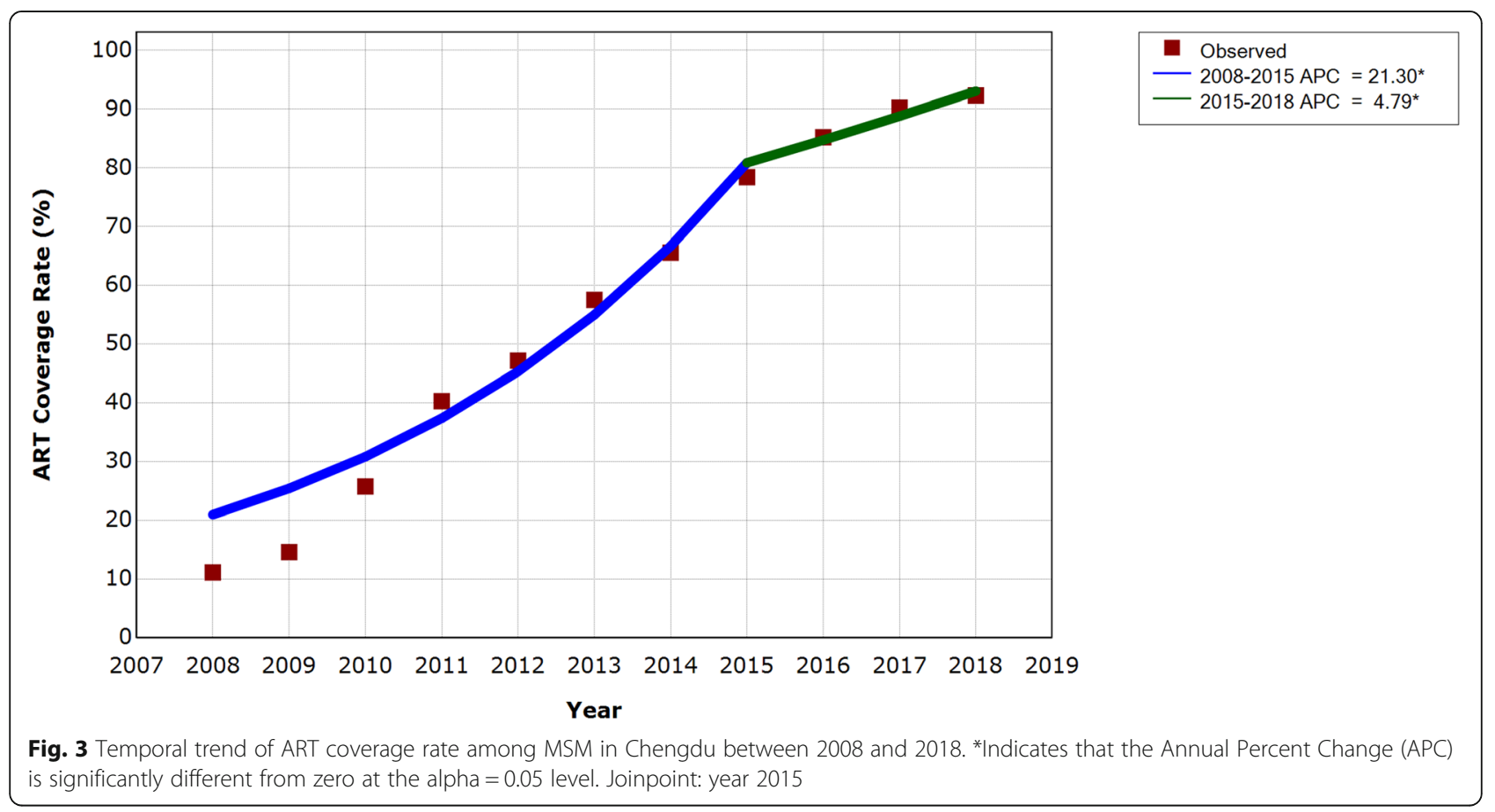


Table 2 Results of segmented regression models for HIV sentinel seroprevalence and annual reported HIV cases among MSM before and after Treat All policy

\begin{tabular}{|c|c|c|c|c|}
\hline & Coefficient & Standard error & $P$ value & 95\% Confidence interval (CI) \\
\hline \multicolumn{5}{|c|}{ HIV sentinel seroprevalence ${ }^{a}$ (Model 1 ) } \\
\hline$\beta_{0}$ (Baseline) & 0.1123 & 0.0059 & $<0.001^{* * *}$ & $(0.0982,0.1264)$ \\
\hline$\beta_{1}$ (Structural trend) & 0.0087 & 0.0015 & $0.001^{* * *}$ & $(0.0051,0.0124)$ \\
\hline$\beta_{2}$ (Change in level) & -0.0005 & 0.0087 & 0.959 & $(-0.0210,0.0201)$ \\
\hline$\beta_{3}$ (Change in trend) & -0.0308 & 0.0025 & $<0.001^{* * *}$ & $(-0.0366,-0.0250)$ \\
\hline \multicolumn{5}{|c|}{ Newly reported HIV cases ${ }^{\text {b }}$ (Model 2 ) } \\
\hline$\beta_{0}$ (Baseline) & 63.35 & 37.33 & 0.133 & $(-24.92,151.62)$ \\
\hline$\beta_{1}$ (Structural trend) & 116.38 & 9.68 & $<0.001^{* * *}$ & $(93.48,139.28)$ \\
\hline$\beta_{2}$ (Change in level) & 463.23 & 54.65 & $<0.001^{* * *}$ & $(334.01,592.45)$ \\
\hline$\beta_{3}$ (Change in trend) & -158.28 & 15.47 & $<0.001^{* * *}$ & $(-194.87,-121.69)$ \\
\hline
\end{tabular}

${ }^{a}$ calculated with number of sampled MSM in the annual sentinel survey conducted in Chengdu as denominator and confirmed HIV cases from those MSM as numerator

b newly confirmed HIV cases in CRIMS whose route of infection was male homosexual transmission and address was Chengdu city

newly reported HIV cases, a relative $24.55 \%$ decrease in other words, four years after the treatment policy intervention.

\section{Discussion}

Our study showed HIV sentinel seroprevalence and annual reported HIV cases declined, and ART coverage rate increased after Treat All policy was implemented in MSM population in Chengdu, illuminating the potential of immediate ART initiation to contain the HIV epidemic. It also suggested that in real-world conditions, early ART could be potentially efficacious in curbing HIV transmission at population level, which were consistent with previous studies $[48,49]$.

Treat All policy contributed to reducing new HIV infections at population level among MSM and had a sustained impact. According to ITS analysis, compared to upward trends during the pre-policy period, there were statistically significant downward trends in HIV sentinel seroprevalence and annual reported HIV cases since the policy intervention, indicating the growing trends were reversed after Treat All policy implementation. Increased ART coverage is associated with decreased HIV incidence $[13,49,50]$, and the huge progress made in ART coverage reflected Treat All policy helped ensure more efficient ART delivery and prompted more asymptomatic MSM living with HIV to undergo treatment, thus potentially turning down population-level HIV transmission, which were in line with similar real-world studies to show expanded access to ART helps curb the growth of HIV epidemics [48, 49].

The second "90" of UNAIDS's "90-90-90" goals, which is $90 \%$ of those diagnosed with HIV receive ART, was achieved among MSM in this region. As is the case in this study, ART coverage rate reached $92.29 \%$ among MSM in 2018 (an absolute increase of $81.18 \%$ compared to that in 2008). After CD4+ cell threshold for ART eligibility was abolished, great progress has been made in terms of the proportion of HIV-positive MSM who're receiving ART, which was also observed in previous study [13]. Scaling up ART coverage has been important component in actions against the growing HIV epidemic among MSM [30]. Increased ART coverage reflects direct effect of lowering the treatment eligibility threshold (CD4+ cell count), serving as the intermediate path from decreased threshold for ART eligibility to new HIV infection reduction. While real-world studies evaluating impacts of lowering treatment threshold on ART coverage and HIV epidemics were scarce, series of clinical trials concerning this aspect were carried out. Both the TasP (ANRS 12249) and the HPTN 071 (PopART) trials conducted in South Africa didn't see increased ART coverage or reduced incidence in the immediate ART arm compared to the control group [27, 51]. The absence of decreased incidence can be explained by incident HIV infections from outside of the study population in light of multiple sex partners behavior among MSM [52], suggesting ART accessibility for "all" is critical in fighting against HIV. Besides, low treatment coverage in the trials added to the evidence of challenging situations where lack of funding, manpower and so on may emerge in trial settings, not to mention in realworld settings with more restricted budgets. Nevertheless, Treat All policy bore inspiring outcomes, which can be due to great work and robust funding from local and national authorities and organizations, plus budgets guarantee from China's National Free Antiretroviral Treatment Program [53].

Lagged effect, referring to impacts taking time to manifest after intervention [54], wasn't observed in our study, which can be due to that the HIV epidemic was in dire situation among MSM in Chengdu and MSM 
since has been the key intervention group, so that quick and great efforts were taken to roll out Treat All policy citywide. Besides, concurrent endeavors like expanded HIV testing and HIV/AIDS supportive environment construction may also play a part.

It should be noted that those recruited in the annual sentinel surveillance at venues frequented by MSM (like gay bars, bath room, etc.) are more likely to be sexually active with more risky sexual behaviors, thereby HIV sentinel seroprevalence may be somewhat overestimated [37]. But this influence isn't prone to vary over time. Moreover, the proportion of previously HIV infected MSM in the surveyed sample has remained stable since the national HIV surveillance system scale-up in 2008, so HIV seroprevalence since 2008 can reasonably reflect changes in the trend of new HIV infections among MSM [37]. Hence HIV seroprevalence obtained from serial cross-sectional surveys could still reveal information about changing trends of the HIV epidemic and be used to evaluate effects of HIV prevention and control efforts among MSM.

Additionally, despite a descending trend since 2014, annual reported HIV cases among MSM remained at a relatively high level, compared with that in the prepolicy period. This may be attributed to the following aspects: optimization of national HIV information system making sure more complete and timely case reporting; increased number of MSM community-based organizations (CBOs) and their frequent activities prompting more hidden HIV-positive MSM to be detected; and rising number of HIV-positive MSM with an ongoing HIV epidemic in MSM population whose size is growing as well.

Our study reveals practical value of Treat All policy to potentially reduce HIV infection at population level, while challenges remain at the frontline. Treat All policy demands enormous investments to achieve effective ART expansion and sustained viral suppression, the ultimate goal of HIV control, which requires sustained ART accessibility. However, this goal is yet a challenge to be overcome financially and administratively, especially for low- and middle-income countries where resources of all sorts are limited [55]. Furthermore, due to social and structural factors like stigmatization, key populations affected by HIV including MSM have poor access to HIV services. But they are groups who benefit most from early ART [56]. Core-group theory posits that prevention among a relatively few at the highest risk of acquisition and transmission, can protect many along a potential transmission chain $[57,58]$. Therefore, MSM have been and will still be a priority group in HIV prevention and control strategies globally.

To maximize the benefits of Treat All policy, experience can be learned from Chengdu and measures need to be taken from a systematic perspective. First of all, expand HIV testing in that it underlies implementation of nearly all other interventions. As supplement to voluntary counseling and testing, home-based "HIV selftesting" was suggested by WHO to improve HIV testing [59]. There are self-testing kits available now in Chengdu. Moreover, to encourage engagement, HIV testing services can be applied on CBO's websites and provided in places frequented by MSM, which have helped improve testing volumes in Chengdu. Second, strengthen collaboration with international, governmental and non-governmental organizations to guarantee robust funding. Chengdu CDC worked with UNAIDS to successfully execute strategic planning of AIDS prevention and treatment for MSM (2011-2015) to facilitate field work and community empowering. Besides, during China's "12th five-year plan on AIDS prevention and treatment", Chengdu CDC collaborated with China $\mathrm{CDC}$, the central institution in Beijing, to conduct questionnaire interviewing and serological testing among MSM. Finally, a Continuum of HIV Services should be established with $\mathrm{CBOs}$, CDCs and hospitals coordinated as a whole, to improve health care efficiency, expand coverage and facilitate sustained accessibility. One-stop HIV testing, confirmation and treatment services are now available at the same hospital in Chengdu. The "Tongle" ("happy together") organization, a Chengdubased CBO which serves as a hinge to link MSM, local CDCs and hospitals, sets as a good example that support from peers and CBO workers trusted by MSM are necessary while delivering HIV services.

\section{Limitations}

There are some limitations in this study. Firstly, HIV sentinel seroprevalence is obtained using non-probability sampling methods, which might lead to selection bias and undermine representativeness [39]. However, probability sampling is not practical considering the hidden nature of MSM population. The same sampling design used in each survey round guarantees any bias caused by nonrandom sampling can be assumed to be relatively stable [40], so samples of sub-groups of MSM still provide important information of the HIV epidemic as well as effects of policy intervention. Secondly, the number of time points used in ITS models was relatively small. Although there were only 6 and 5 time points before and after the policy intervention respectively, the analysis outcomes presented statistically significant trends, indicating robust statistical power to detect changes in the trends. Thirdly, viral suppression rate, the third UNAIDS "90" goal, is supposed to be taken into consideration in treatment policy evaluation. It wasn't included due to data incompletion in the early period when the information system was being built up. Further research should 
work on evaluation of viral suppression to fully interpret impacts of HIV policy interventions. Finally, an observational study, our study was based on an ecological perspective, potential confounding might not be controlled. Any causal relationships can't be assumed between the policy intervention and the analyzed indicators. Though ITS analysis didn't control for other events that may have influenced the outcome, single group time series still address threats to internal validity and provide a methodologically acceptable design for studying intervention effects [54]. Besides, our study is limited in Chengdu, hence careful consideration and comparisons of geographical and subpopulation patterns of HIV epidemics among populations at provincial and national level should be taken before cautious generalization to broader populations.

\section{Conclusions}

The policy of immediate ART after diagnosis in MSM population in Chengdu improved ART coverage, enabling more MSM living with HIV to receive treatment. And the downward trends of HIV sentinel seroprevalence and newly reported HIV cases demonstrated the potential of Treat All policy to turn the tide of the rampant HIV epidemic in MSM population. A real-world evaluation of treatment policy intervention among MSM, our study laid foundation for future assessment of HIV prevention and control policy using longitudinal routine data from health information systems, particularly in resource-limited low- and middle-income countries. In the meanwhile, further coordinated strategies are needed to maximize the benefits of early ART to contain HIV epidemics.

\section{Abbreviations}

ART: Antiretroviral therapy/treatment; AIDS: Acquired immunodeficiency syndrome; APC: Annual Percent Change; AAPC: Average Annual Percent Change; CDC: Center for Disease Control and Prevention; CRIMS: National HIV/AIDS Comprehensive Response Information Management System; Cl: Confidence interval; HIV: Human immunodeficiency virus; ITS: Interrupted time series; MSM: Men who have sex with men; PLHIV: People living with HIV; UNAIDS: The Joint United Nations Program on HIV and AIDS; WHO: World Health Organization

\section{Acknowledgements}

We thank all the staff at Chengdu CDC for their field work of conducting the annual sentinel surveillance survey and their routine work of collecting and archiving loads of data every day. We also thank health care practitioners at every level for HIV detecting and timely registering in CRIMS, as well as community workers who help convene MSM to participate in sentinel surveillance survey and facilitate all the field work.

\section{Authors' contributions}

$\mathrm{CZ}$ and $\mathrm{QH}$ conceived of the study. CZ, QH and CW made the statistical plan. QH, ZD1, ZD2 and QZ collected and aggregated the research data. CW and BZ performed the analyses. CW wrote the manuscript. All authors advised on the results interpretation and helped improve the manuscript. All authors have read and approved the final manuscript.

\section{Funding}

No funding.

\section{Availability of data and materials}

The data that support the findings of this study are not publicly available due to data protection and confidentiality and restrictions apply to the availability of these data, which were used under license for the current study. Data are however available from the authors upon reasonable request and with permission of Chengdu CDC.

\section{Declarations}

\section{Ethics approval and consent to participate}

This study was considered to be a policy evaluation research and didn't require research ethical approval by the Ethics Committee. We inquired IRB of Sichuan University and the board suggested ethics approval be waived given that all data have been completely deidentified and aggregated before access and analysis. All the data used in the study were collected with permission and in accordance with national regulation by Chengdu Center for Disease Control and Prevention.

\section{Consent for publication}

Not applicable.

\section{Competing interests}

The authors declare that they have no competing interests.

Received: 27 July 2020 Accepted: 7 March 2021

Published online: 08 April 2021

\section{References}

1. World Health Organization (WHO). HIV/AIDS Key facts (15 November 2019) [Available from: https://www.who.int/en/news-room/fact-sheets/detail/hiv-a ids.

2. Zhang L, Chow EP, Jing J, Zhuang X, Li X, He M, et al. HIV prevalence in China: integration of surveillance data and a systematic review. Lancet Infect Dis. 2013;13(11):955-63. https://doi.org/10.1016/\$1473-3099(13)702457.

3. National Health Commission of the People's Republic of China. Transcript of Regular Press Conference National Health Commission of the People's Republic of China. 2019 [Available from: http://www.nhc.gov.cn/wjw/xwdt/2 01811/b0ca3817224e44899a3248a0f6e48948.shtml.

4. Wang L, Wang L, Norris JL, Li DM, Guo W, Ding ZW, et al. HIV prevalence and influencing factors analysis of sentinel surveillance among men who have sex with men in China, 2003-2011. Chin Med J. 2012;125(11):1857-61.

5. UNAIDS. Global HIV \& AIDS statistics - 2019 fact sheet. UNAIDS. Available from: https://www.unaids.org/en/resources/fact-sheet. Accessed 31 Dec 2019.

6. Riddell J, Amico KR, Mayer KH. HIV Preexposure prophylaxis: a review. JAMA 2018;319(12):1261-8. https://doi.org/10.1001/jama.2018.1917.

7. Johnson LF, Mossong J, Dorrington RE, Schomaker M, Hoffmann CJ, Keiser $\mathrm{O}$, et al. Life expectancies of South African adults starting antiretroviral treatment: collaborative analysis of cohort studies. PLoS Med. 2013;10(4): e1001418.

8. Mills EJ, Bakanda C, Birungi J, Chan K, Ford N, Cooper CL, et al. Life Expectancy of Persons Receiving Combination Antiretroviral Therapy in Low-Income Countries: A Cohort Analysis From Uganda. Ann Internal Med. 2011;155(4):209.

9. O'Connor J, Vjecha MJ, Phillips AN, Angus B, Cooper D, Grinsztejn B, Lopardo G, Das S, Wood R, Wilkin A, Klinker H, Kantipong P, Klingman KL, Jilich D, Herieka E, Denning E, Abubakar I, Gordin F, Lundgren JD, INSIGHT START study group. Effect of immediate initiation of antiretroviral therapy on risk of severe bacterial infections in HIV-positive people with CD4 cell counts of more than 500 cells per $\mu \mathrm{L}$ : secondary outcome results from a randomised controlled trial. Lancet HIV. 2017;4(3):e105-e12. https://doi.org/1 0.1016/S2352-3018(16)30216-8.

10. Lodi S, Sharma S, Lundgren JD, Phillips AN, Cole SR, Logan R, Agan BK, Babiker A, Klinker H, Chu H, Law M, Neaton JD, Hernán MA, INSIGHT Strategic Timing of AntiRetroviral Treatment (START) study group. The perprotocol effect of immediate versus deferred antiretroviral therapy initiation. AIDS. 2016;30(17):2659-63. https://doi.org/10.1097/QAD.0000000000001243.

11. Lifson AR, Grund B, Gardner EM, Kaplan R, Denning E, Engen N, Carey CL, Chen F, Dao S, Florence E, Sanz J, Emery S, INSIGHT START Study Group. Improved quality of life with immediate versus deferred initiation of 
antiretroviral therapy in early asymptomatic HIV infection. AIDS. 2017;31(7): 953-63. https://doi.org/10.1097/QAD.0000000000001417.

12. Cohen MS, Chen YQ, McCauley M, Gamble T, Hosseinipour MC, Kumarasamy N, Hakim JG, Kumwenda J, Grinsztejn B, Pilotto JH, Godbole SV, Mehendale S, Chariyalertsak S, Santos BR, Mayer KH, Hoffman IF, Eshleman SH, Piwowar-Manning E, Wang L, Makhema J, Mills LA, de Bruyn G, Sanne I, Eron J, Gallant J, Havlir D, Swindells S, Ribaudo H, Elharrar V, Burns D, Taha TE, Nielsen-Saines K, Celentano D, Essex M, Fleming TR, HPTN 052 Study Team. Prevention of HIV-1 infection with early antiretroviral therapy. N Engl J Med. 2011;365(6):493-505. https://doi.org/10.1056/ NEJMoa1105243.

13. McManus H, Callander D, Donovan B, Russell DB, O'Connor CC, Davies SC, Lewis DA, Hellard ME, Chen MY, Petoumenos K, Varma R, Cogle A, Boyd MA, Grulich A, Pollard J, Medland N, Fairley CK, Guy RJ. Early initiation of antiretroviral therapy for people newly diagnosed with HIV infection in Australia: trends and predictors, 2004-2015. Med J Aust. 2019;210(6):269-75. https://doi.org/10.5694/mja2.50006.

14. Caby F, French Hosp Database HF-A. CD4(+)/CD8(+) ratio restoration in long-term treated HIV-1-infected individuals. Aids. 2017;31(12):1685-95.

15. May MT, Gompels M, Delpech V, Porter K, Orkin C, Kegg S, Hay P, Johnson M, Palfreeman A, Gilson R, Chadwick D, Martin F, Hill T, Walsh J, Post F, Fisher M, Ainsworth J, Jose S, Leen C, Nelson M, Anderson J, Sabin C, UK Collaborative HIV Cohort (UK CHIC) Study. Impact on life expectancy of HIV1 positive individuals of CD4(+) cell count and viral load response to antiretroviral therapy. Aids. 2014;28(8):1193-202. https://doi.org/10.1097/QA D.0000000000000243.

16. Zhang F, Dou Z, Ma Y, Zhang Y, Zhao Y, Zhao D, Zhou S, Bulterys M, Zhu H, Chen RY. Effect of earlier initiation of antiretroviral treatment and increased treatment coverage on HIV-related mortality in China: a national observational cohort study. Lancet Infect Dis. 2011;11(7):516-24. https://doi. org/10.1016/S1473-3099(11)70097-4.

17. Cohen MS, Chen YQ, McCauley M, Gamble T, Hosseinipour MC, Kumarasamy N, Hakim JG, Kumwenda J, Grinsztejn B, Pilotto JH, Godbole SV, Chariyalertsak S, Santos BR, Mayer KH, Hoffman IF, Eshleman SH, Piwowar-Manning E, Cottle L, Zhang XC, Makhema J, Mills LA, Panchia R, Faesen S, Eron J, Gallant J, Havlir D, Swindells S, Elharrar V, Burns D, Taha TE, Nielsen-Saines K, Celentano DD, Essex M, Hudelson SE, Redd AD, Fleming TR, HPTN 052 Study Team. Antiretroviral therapy for the prevention of HIV-1 transmission. N Engl J Med. 2016;375(9):830-9. https:/doi.org/10.1056/NEJMoa1600693.

18. Petersen M, Balzer L, Kwarsiima D, Sang N, Chamie G, Ayieko J, Kabami J, Owaraganise A, Liegler T, Mwangwa F, Kadede K, Jain V, Plenty A, Brown L, Lavoy G, Schwab J, Black D, van der Laan M, Bukusi EA, Cohen CR, Clark TD, Charlebois E, Kamya M, Havlir D. Association of Implementation of a universal testing and treatment intervention with HIV diagnosis, receipt of antiretroviral therapy, and viral suppression in East Africa. Jama-J Am Med Assoc. 2017;317(21):2196-206. https://doi.org/10.1001/jama.2017.5705.

19. Makhema J, Wirth KE, Pretorius Holme M, Gaolathe T, Mmalane M, Kadima E, Chakalisa U, Bennett K, Leidner J, Manyake K, Mbikiwa AM, Simon SV, Letlhogile R, Mukokomani K, van Widenfelt E, Moyo S, Lebelonyane R, Alwano MG, Powis KM, Dryden-Peterson SL, Kgathi C, Novitsky V, Moore J, Bachanas P, Abrams W, Block L, el-Halabi S, Marukutira T, Mills LA, Sexton C, Raizes E, Gaseitsiwe S, Bussmann H, Okui L, John O, Shapiro RL, Pals S, Michael H, Roland M, DeGruttola V, Lei Q, Wang R, Tchetgen Tchetgen E, Essex M, Lockman S. Universal testing, expanded treatment, and incidence of HIV infection in Botswana. N Engl J Med. 2019;381(3):230-42. https://doi. org/10.1056/NEJMoa1812281.

20. Saag MS, Benson CA, Gandhi RT, Hoy JF, Landovitz RJ, Mugavero MJ, Sax PE, Smith DM, Thompson MA, Buchbinder SP, del Rio C, Eron JJ Jr, Fätkenheuer G, Günthard HF, Molina JM, Jacobsen DM, Volberding PA. Antiretroviral drugs for treatment and prevention of HIV infection in adults 2018 recommendations of the international antiviral society-USA panel. Jama-J Am Med Assoc. 2018;320(4):379-96. https://doi.org/10.1001/jama.2018.8431.

21. The INSIGHT START Study Group. Initiation of antiretroviral therapy in early asymptomatic HIV infection. N Engl J Med. 2015;373(9):795-807. https://doi. org/10.1056/NEJMoa1506816.

22. Danel C, Moh R, Gabillard D, Badje A, Le Carrou J, Ouassa T, et al. A trial of early Antiretrovirals and isoniazid preventive therapy in Africa. N Engl J Med. 2015;373(9):808-22. https://doi.org/10.1056/NEJMoa1507198.

23. World Health Organization (WHO). Policy Brief: Consolidated Guidelines on the Use of Antiretroviral Drugs for Treating and Preventing HIV Infection:
What's New 2015 [Available from: http://apps.who.int/iris/bitstream/10665/1 98064/1/9789241509893_eng.pdf?ua=1.

24. Mayer KH, Krakower DS. Antiretrovirals for HIV treatment and prevention the challenges of success. Jama-Journal of the American Medical Association. 2016;316(2):151-3. https://doi.org/10.1001/jama.2016.8902.

25. Havlir D, Charlebois E, Balzer L, Clark T, Kwarisiima D, Ayieko J, et al. SEARCH community cluster randomized study of HIV "test and treat" using multidisease approach and streamlined care in rural Uganda and Kenya. J Int AIDS Soc. 2018;21:164-5

26. Iwuji CC, Orne-Gliemann J, Larmarange J, Balestre E, Thiebaut R, Tanser F, Okesola N, Makowa T, Dreyer J, Herbst K, McGrath N, Bärnighausen T, Boyer S, de Oliveira T, Rekacewicz C, Bazin B, Newell ML, Pillay D, Dabis F, Bärnighausen T, Herbst K, Iwuji C, Makowa T, Naidu K, Newell ML, Okesola N, de Oliveira T, Pillay D, Rochat T, Tanser F, Viljoen J, Zuma T, McGrath N, Balestre E, Dabis F, Karcher S, Orne-Gliemann J, Plazy M, Prague M, Thiébaut R, Tiendrebeogo T, Boyer S, Donfouet H, Gosset A, March L, Protopopescu C, Spire B, Calmy A, Larmarange J, Inghels M, Diallo H, Calvez V, Derache A, Marcelin AG, Dray-Spira R, Lert F, el Farouki K, Lessells R, Freedberg K, Imrie J, Chaix ML, Newell C, Hontelez J, Bazin B, Rekacewicz C. Universal test and treat and the HIV epidemic in rural South Africa: a phase 4, open-label, community cluster randomised trial. Lancet HIV. 2018;5(3):E116-E25. https:// doi.org/10.1016/S2352-3018(17)30205-9.

27. Hayes RJ, Donnell D, Floyd S, Mandla N, Bwalya J, Sabapathy K, et al. Effect of Universal Testing and Treatment on HIV Incidence - HPTN 071 (PopART). New England J Med. 381(3):207-18.

28. Granich RM, Gilks CF, Dye C, De Cock KM, Williams BG. Universal voluntary HIV testing with immediate antiretroviral therapy as a strategy for elimination of HIV transmission: a mathematical model. Lancet. 2009; 373(9657):48-57. https://doi.org/10.1016/S0140-6736(08)61697-9.

29. Sorensen SW, Sansom SL, Brooks JT, Marks G, Begier EM, Buchacz K, et al. A mathematical model of comprehensive test-and-treat services and HIV incidence among men who have sex with men in the United States. PLoS ONE [Electronic Resource]. 2012;7(2):e29098.

30. Beyrer C, Baral SD, Collins C, Richardson ET, Sullivan PS, Sanchez J, Trapence G, Katabira E, Kazatchkine M, Ryan O, Wirtz AL, Mayer KH. The global response to HIV in men who have sex with men. Lancet. 2016;388(10040): 198-206. https://doi.org/10.1016/S0140-6736(16)30781-4.

31. Chinese Center for Disease Control. Public Health Science Data Center. Available from: http://www.phsciencedata.cn/Share/edtShareNew.jsp?id=394 03. Accessed 6 Feb 2020.

32. Mao Y, Wu Z, Poundstone K, Wang C, Qin Q, Ma Y, et al. Development of a unified web-based national HIV/AIDS information system in China. Int J Epidemiol. 2010;39:1179-89.

33. Sun J, Liu H, Li H, Wang L, Guo H, Shan D, et al. Contributions of international cooperation projects to the HIV/AIDS response in China. Int J Epidemiol. 2010;39:I14-20.

34. Wang L, Wang N. HIV/AIDS epidemic and the development of comprehensive surveillance system in China with challenges. Chin Med J. 2010;123(23):3495-500.

35. Zhang L, Chow EPF, Zhang J, Jing J, Wilson DP. Describing the Chinese HIV surveillance system and the influences of political structures and social stigma. Open AIDS J. 2012;6(1):163-8. https://doi.org/10.2174/18746136012 06010163.

36. Xu J, Mao Y. Current status and prospect of China's national HIV/AIDS comprehensive response information management system (CRIMS). Chinese JAIDS STD. 2016;22(9):756-8.

37. Ge L, Li D, Li P, Guo W, Cui Y. Population specific sentinel surveillance for HIV infection, syphilis and HCV infection in China during 2010-2015. DIS SURVEILLANCE. 2017;32(2):111-7.

38. Qiao D, Liu Z, Dong Z, Li W, Yang H. Sentinel surveillance and factors affecting HIV infection among MSM in Zhengzhou, 2016-2018. Modern Preventive Medicine. 2019;46(19):3603-7.

39. Strickler $\mathrm{H}$, Hoover DR, Dersimonian R. Problems in interpreting HIV sentinel seroprevalence studies. Ann Epidemiol. 1995;5(6):447-54. https://doi.org/10.1 016/1047-2797(95)00070-4.

40. Zhang D, Bi P, Hiller JE, LV F. Web-based HIV/AIDS behavioral surveillance among men who have sex with men: potential and challenges. Int J Infect Dis. 2008;12(2):126-31. https://doi.org/10.1016/j.ijid.2007.06.007.

41. Beyrer C, Baral SD, van Griensven F, Goodreau SM, Chariyalertsak S, Wirtz AL, Brookmeyer R. Global epidemiology of HIV infection in men who have sex 
with men. Lancet. 2012;380(9839):367-77. https://doi.org/10.1016/50140-673 6(12)60821-6.

42. Chen KT, Chang HL, Chen $\mathrm{CT}$, Chen YA. The changing face of the HIV epidemic in Taiwan: a new challenge for public health policy strategies. AIDS Patient Care STDs. 2009;23(3):195-201. https://doi.org/10.1089/apc.2 008.0047.

43. Das M, Chu PL, Santos GM, Scheer S, Vittinghoff E, McFarland W, et al. Decreases in community viral load are accompanied by reductions in new HIV infections in San Francisco. PLoS One. 2010;5(6):e11068.

44. Wand H, Wilson D, Yan P, Gonnermann A, McDonald A, Kaldor J, Law M. Characterizing trends in HIV infection among men who have sex with men in Australia by birth cohorts: results from a modified back-projection method. J Int AIDS Soc. 2009;12(1):19. https://doi.org/10.1186/1758-2 652-12-19.

45. Bernal JL, Cummins S, Gasparrini A. Interrupted time series regression for the evaluation of public health interventions: a tutorial. Int J Epidemiol. 2017;46(1):348-55. https://doi.org/10.1093/ije/dyw098.

46. Lagarde M. How to do (or not to do) ... Assessing the impact of a policy change with routine longitudinal data. Health Policy Plan. 2011;27(1):76-83. https://doi.org/10.1093/heapol/czr004.

47. Judge GG. The theory and practice of econometrics: New York: Wiley; 1985.

48. Frank Tanser TB. Erofili Grapsa, Jaffer Zaidi, Marie-Louise Newell. High coverage of ART associated with decline in risk of HIV Acquisition in Rural KwaZulu-Natal, South Africa. Science. 2013;339(6122):966-71. https://doi. org/10.1126/science.1228160.

49. Montaner JS, Lima VD, Harrigan PR, Lourenco L, Yip B, Nosyk B, et al. Expansion of HAART coverage is associated with sustained decreases in HIV/AIDS morbidity, mortality and HIV transmission: the "HIV treatment as prevention" experience in a Canadian setting. PLoS One. 2014;9(2):e87872. https://doi.org/10.1371/journal.pone.0087872.

50. Lima VD, Johnston K, Hogg RS, Levy AR, Harrigan PR, Anema A, Montaner JSG. Expanded access to highly active antiretroviral therapy: a potentially powerful strategy to curb the growth of the HIV epidemic. J Infect Dis. 2008;198(1):59-67. https://doi.org/10.1086/588673.

51. Tanser F, Kim HY, Vandormael A, Iwuji C, Barnighausen T. Opportunities and challenges in HIV treatment as prevention research: results from the ANRS 12249 cluster-randomized trial and associated population cohort. Current Hiv/Aids Reports. 2020;17(2):97-108. https://doi.org/10.1007/s1 1904-020-004 87-1.

52. Koblin BA, Husnik MJ, Colfax G, et al. Risk factors for HIV infection among men who have sex with men. AIDS. 2006;20(5):731-9. https://doi.org/10.1 097/01.aids.0000216374.61442.55.

53. Chinese Center for Disease Control and Prevention. National Handbook of Free HIV Antiviral Treatment (4th edition): People's Medical Publishing House; 2016.

54. Wagner AK, Soumerai SB, Zhang F, Ross-Degnan D. Segmented regression analysis of interrupted time series studies in medication use research. J Clin Pharm Ther. 2002;27(4):299-309. https://doi.org/10.1046/j.1365-2710.2002. 00430.x.

55. Baral S, Rao A, Sullivan P, Phaswana-Mafuya N, Diouf D, Millett G, Musyoki H, Geng E, Mishra S. The disconnect between individual-level and populationlevel goatee. HIV prevention benefits of antiretroviral treatment. Lancet HIV. 2019:6(9):E632-E8. https://doi.org/10.1016/S2352-3018(19)30226-7.

56. Molina J-M, Grund B, Gordin F, Williams I, Schechter M, Losso M, Law M, Ekong E, Mwelase N, Skoutelis A, Wiselka MJ, Vandekerckhove L, Benfield T, Munroe D, Lundgren JD, Neaton JD, INSIGHT START study group. Which HIV-infected adults with high CD4 T-cell counts benefit most from immediate initiation of antiretroviral therapy? A post-hoc subgroup analysis of the START trial. The Lancet HIV. 2018;5(4):e172-e80. https://doi.org/10.101 6/S2352-3018(18)30003-1.

57. Garnett GP. Role of herd immunity in determining the effect of vaccines against sexually transmitted disease. J Infect Dis. 2005;191(s1):S97-S106. https://doi.org/10.1086/425271.

58. Anderson RMR. Infectious diseases of humans: dynamics and control. Oxford: Oxford University Press; 1991.

59. World Health Organization (WHO). WHO recommends HIV self-testing 2016 2016 [Available from: http://apps.who.int/iris/bitstream/10665/251549/1/ WHO-HIV-2016.21-eng.pdf?ua=1.

\section{Publisher's Note}

Springer Nature remains neutral with regard to jurisdictional claims in published maps and institutional affiliations.
Ready to submit your research? Choose BMC and benefit from:

- fast, convenient online submission

- thorough peer review by experienced researchers in your field

- rapid publication on acceptance

- support for research data, including large and complex data types

- gold Open Access which fosters wider collaboration and increased citations

- maximum visibility for your research: over $100 \mathrm{M}$ website views per year

At BMC, research is always in progress.

Learn more biomedcentral.com/submissions 